\title{
Chorioretinal biopsy in a patient with leukaemia
}

\author{
DAVID TAYLOR, ${ }^{1}$ SUSAN DAY,${ }^{1}$ KARIN TIEDEMANN,${ }^{2}$ JUDITH CHESSELS,${ }^{2}$ \\ W. C. MARSHALL, ${ }^{3}$ AND I. J. CONSTABLE ${ }^{4}$ \\ From the 'Department of Ophthalmology, the ${ }^{2}$ Department of Haematology, and the ${ }^{3}$ Department of \\ Infectious Diseases, the Hospital for Sick Children, Great Ormond Street, London WC1; and the \\ ${ }^{4}$ University Department of Ophthalmology, Royal Perth Hospital, Perth 6001, Western Australia
}

SUMMARY The diagnosis of necrotising viral chorioretinitis in a child with leukaemia in remission was confirmed by the presence of viral particles on electron microscopy. Biopsy from the blind eye differentiated between leukaemic infiltrates and an infectious process after further investigations initially failed to support either diagnosis. Diagnostic chorioretinal biopsy may be indicated in a blind eye when the differential diagnosis includes conditions with radically different therapeutic alternatives.

The collection of chorioretinal tissue for diagnostic purposes has been considered unsafe until recently. Earlier reports in rabbits, ${ }^{12}$ monkeys, ${ }^{3}$ and man $^{4}$ were associated with operative complications, particularly loss of vitreous humour. Recently a technique ${ }^{5}$ using systemic hypotensive anaesthesia has had no longterm sequelae in $\operatorname{dogs}^{6}$ or operative complications in human volunteers whose eyes were enucleated for malignant melanoma or glaucoma. ${ }^{7}$ We report a case in which chorioretinal biopsy was successfully used for diagnostic and therapeutic reasons in a child with $\mathrm{T}$ cell leukaemia in remission.

\section{Case report}

A 7-year-old boy was admitted to the Hospital for Sick Children, Great Ormond Street, on 18 February 1980 for routine reinvestigation following treatment of acute lymphatic leukaemia of the $\mathrm{T}$ cell type. $\mathrm{He}$ was originally diagnosed as having $\mathrm{T}$ cell leukaemia in September 1977 after presenting with fever and lymphadenopathy. Induction therapy consisted of 4 courses of cyclophosphamide, vincristine, cytosine arabinoside, and prednisolone (COAP). Central nervous system prophylaxis was given as 4 doses of intrathecal methotrexate and 2400 rads cranial irradiation. He received 2 years of maintenance therapy with alternating courses of COAP, 6 mercaptopurine, and methotrexate, and vincristine, adriamycin, and prednisolone every 3 weeks, remain-

Correspondence to David Taylor, FRCS, Department of Ophthalmology, Hospital for Sick Children, Great Ormond Street, London WC1N 3JH. ing in continuous complete remission. The current admission was for testicular biopsy, bone marrow aspiration, and lumbar puncture before the anticipated discontinuation of chemotherapy.

The patient had had no visual symptoms, but the admitting haematologist noted numerous white retinal infiltrates in both eyes. Six weeks earlier the same doctor had found the fundi to be normal. Leukaemic infiltrates were suspected, and ophthalmic consultation was obtained.

The visual acuity was $6 / 24$ in the right eye and $6 / 18$ in the left eye. Both visual fields were constricted to approximately 15 degrees around fixation, tested by confrontation techniques. The patient could distinguish colours of objects in the room but formal testing was not done. Both retinas were deranged, right more than left, by multiple white lesions with a fluffy white border circumscribing a necrotic centre in which the inner retinal layers and much of the choroid and pigment epithelium were completely destroyed (Figs. 1 and 2). Many lesions were confluent. The peripheral retina was extensively involved in each eye, and the right parafoveal region was also affected. The retinal pigment epithelium was deranged with pigment dispersion and clumping. Very few vitreous cells were present posteriorly. Fluorescein angiography showed that the lesions were composed of relatively avascular centres surrounded by leaking retinal vessels.

It was felt that the differential diagnosis lay between leukaemic infiltration and opportunistic viral or fungal retinitis. Initial electron microscopy for cytomegalovirus particles in the urine was negative. Appropriate serum and urine samples for culture were submitted. The patient had a low white blood cell count on 


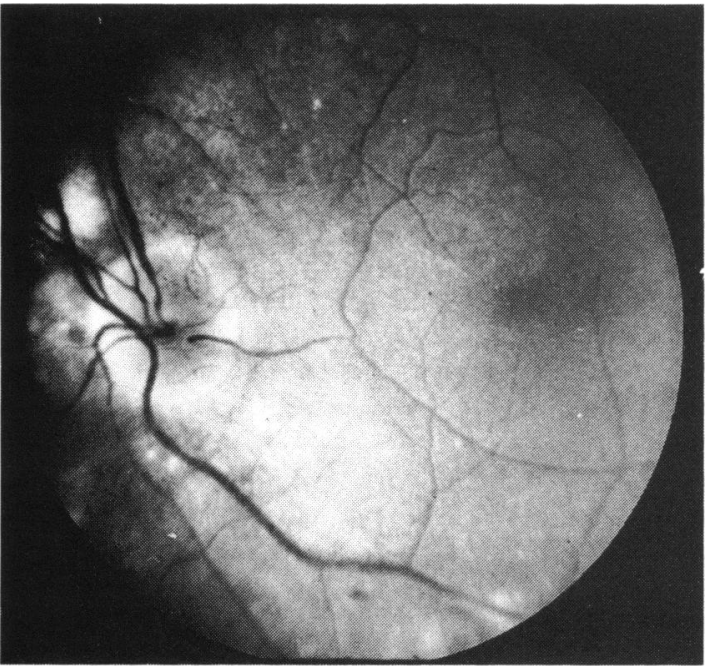

Fig. 1 The left fundus on admission. The macula was largely uninvolved and the acuity 6/18. There were white lesions nasal to the optic disc.

admission to hospital $\left(2 \cdot 1 \times 10^{9} / l\right)$ with $30 \%$ lymphocytes. Within 3 days of admission the vision in the right eye deteriorated to no perception of light due to enlargement of the macular lesion. Trans-scleral chorioretinal biopsy (Fig. 3) of an apparently active

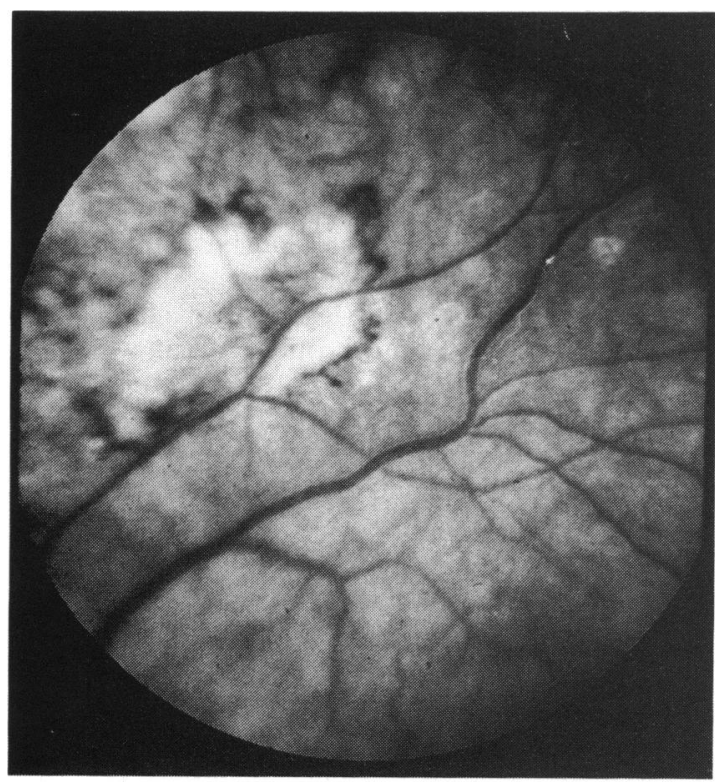

Fig. 2 The left fundus on admission. In the periphery there were several lesions with avascular centres, surrounded by a white ring which itself was surrounded by a small amount of haemorrhage. area of the blind right eye was performed so that a definitive diagnosis might lead to appropriate treatment of the left eye. Cryotherapy to the biopsy site was not used. Vitreous fluid was cultured for virus particles, but no virus was grown.

Bone marrow aspiration, testicular biopsy, and lumbar puncture all confirmed continuing remission.

Because of the strong suspicion of opportunistic infection and the absence of other signs of leukaemic relapse, antiviral therapy was started on the day of biopsy. The patient received a 2-week course of intravenous adenine arabinoside, which was repeated after a 2-week intermission. Additionally, transfer factor was given daily for 1 week and then at weekly intervals.

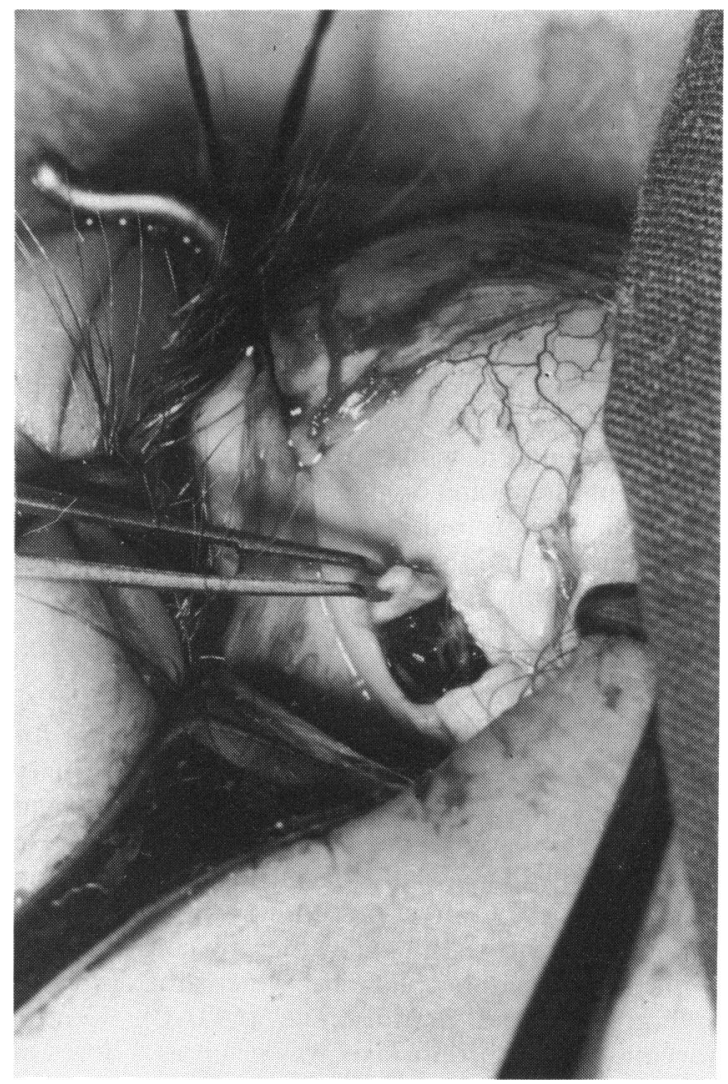

Fig. 3 Chorioretinal biopsy. The suture retracts the right lateral rectus muscle, and a few fibres of the inferior oblique muscle are visible just under the lower arm of the lid speculum. A Desmarre's retractor provides exposure for the $4 \times 4 \mathrm{~mm}$ scleral trapdoor through which the choroid may be seen to bulge. Excision of a $1 \times 3 \mathrm{~mm}$ triangle was accompanied by a gush of non-viscous clear fluid, but there was no haemorrhage. Profound hypotensive anaesthesia was not used. 


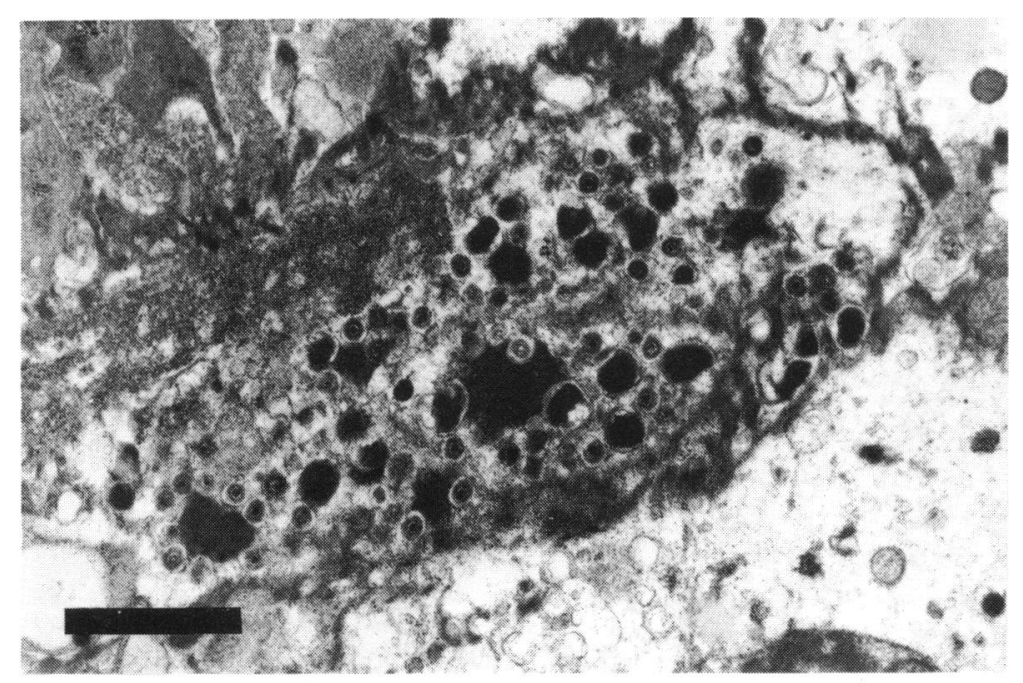

Fig. 4 Ultrastructural studies of the chorioretinal biopsy showed, in one area only, aggregatous of electron-dense bodies, irregularly circular in outline, and smaller lamellated virions. ${ }^{89}$ Bar marker $=1 \mu \mathrm{m}$.
Sections stained with toluidine blue revealed necrotic retinal tissue without either tumour cells or viral inclusion bodies on light microscopy. Electron microscopy (Fig. 4) showed intracytoplasmic particles within choroidal cells; the average measured size was 150 to $200 \mathrm{~nm}$. These were identical to the dense bodies described by Craighead et al. ${ }^{8}$ in cytomegalovirus infected cells. These dense bodies were not virions but were found to have had similar antigenic determinants to the cytomegalovirus envelope and were subsequently clearly separated by special centrifugation techniques. ${ }^{9}$ Subsequently urine and serological studies supported the diagnosis of cytomegalovirus. Four to 6 urine cultures were positive for cytomegalovirus, though electron microscopy of urine repeatedly failed to show virus particles. Additionally the VK strain of papova virus was isolated on urine cultures. The cytomegalovirus complement fixation test antibody titre was positive at $1: 32$ dilutions on 25 February and rose to $1: 256$ by 11 March. Other studies included a rubella HAI antibody titre of 256 , a toxoplasma dye test titre of less than 1:16, and a herpes simplex complement fixation test antibody titre less than 8 .

For 3 months after biopsy the patient's vision in the left eye remained $6 / 9$ to $6 / 12$ despite constriction of visual fields and an ill-defined difficulty in detecting one half of the Ishihara test plates. The averaged skin-electrode electroretinogram showed no definite response recognisable from either eye. Despite anti-viral therapy, however, the necrotising retinitis slowly worsened in the left eye (Figs. 5 and 6) to the point of total blindness in early June. The biopsy site in the right eye has healed without complication.

\section{Discussion}

The advent of multiple agent chemotherapy, and central nervous system radiotherapy prophylaxis, has markedly improved the prognosis for children with leukaemia. ${ }^{1011}$ This treatment, however, may rarely be associated with significant morbidity. Isolated reports have attributed visual loss to toxic drug

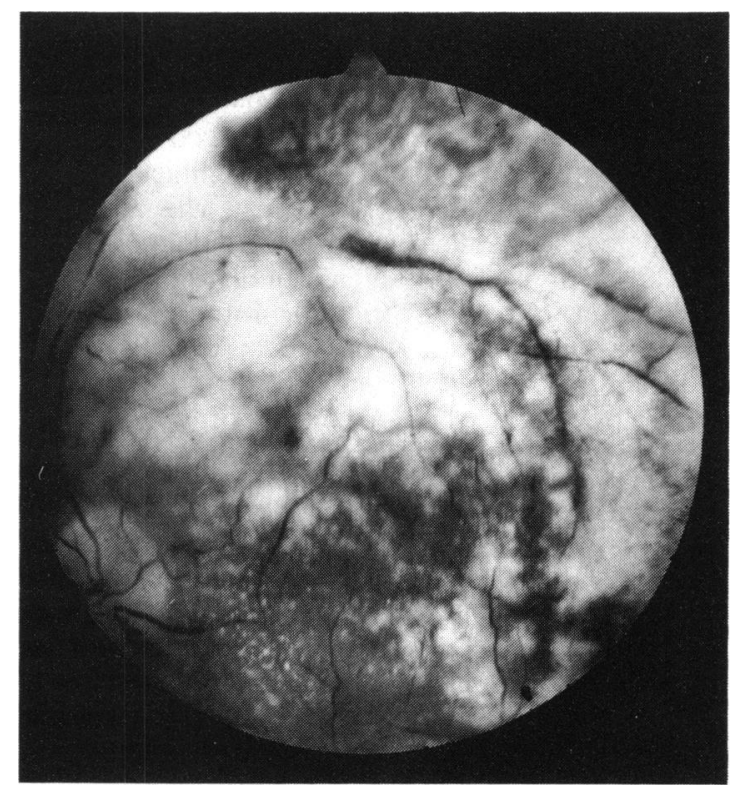

Fig. 5 The left fundus in mid May 1980, 3 months after admission. The acuity was $6 / 18$ despite the extensive fundus changes. 


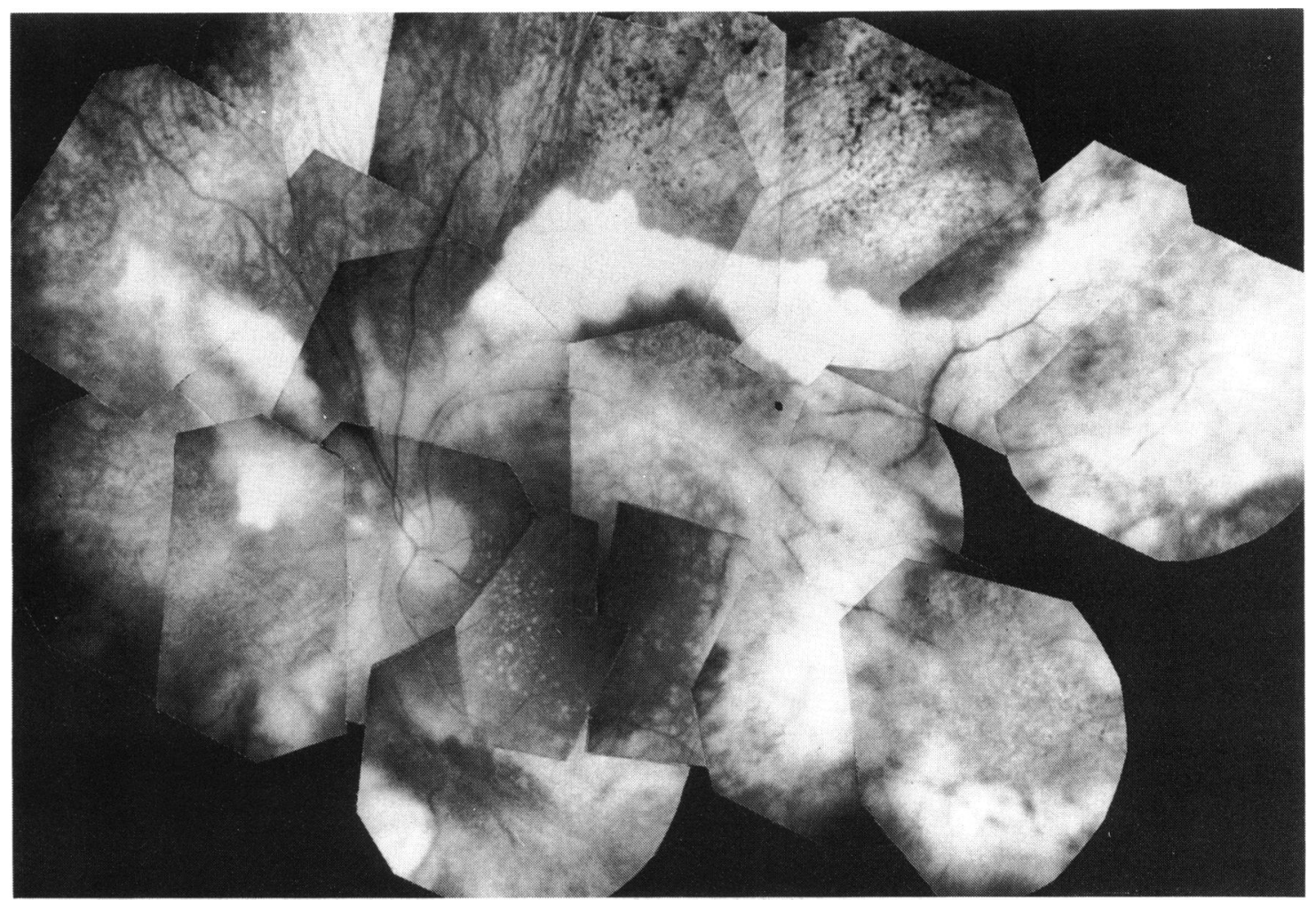

Fig. 6 Montage of the left fundus in late May 1980. The acuity was 6/18. The white lesion above had a well defined edge, especially superiorly. It remained static throughout this admission and probably represents previous inflammatory changes. Peripheral pigment dispersion can be seen above.

effects, ${ }^{12}{ }^{13}$ vascular changes secondary to high dosage radiotheraphy, ${ }^{14}$ or opportunistic infection in the immunosuppressed patient. ${ }^{15-17}$ The clinician must consider these side effects of treatment when evaluating leukaemia patients who either complain of visual disturbance or who have atypical findings on physical examination. It may be very difficult to differentiate infectious infiltrates from leukaemia recurrent within the retina. ${ }^{1618} \mathrm{~A}$ positive diagnosis dictates whether further treatment should consist of more antileukaemic chemotherapy and radiotherapy, or of antiviral, antifungal, or other therapy. Clinical judgment as well as serological and urine studies have thus far been the only guides to diagnosis.

Chorioretinal biopsy can provide a tissue diagnosis within days of the operation. Although the risks involved are not clearly defined, we suspect on the basis of animal experiments that they are low. ${ }^{6} \mathrm{We}$ feel that at present chorioretinal biopsy may be indicated only in a blind eye and then only if a definitive diagnosis would lead to treatment which would either prevent blindness in the fellow eye or arrest a life-threatening systemic process. We do not believe, for instance, that chorioretinal biopsy is indicated in the retinal dystrophies. So far antiviral therapy has been of limited effectiveness against cytomegalovirus ${ }^{19-22}$ but has been shown to be effective against herpes simplex. Although our patient did indeed become completely blind, it is not known whether the treatment he was given delayed this outcome. It is hoped that further advances in antiviral therapy might provide a more specific and effective treatment for cytomegalovirus.

Dr Day was supported by the Fred Gellert Foundation and grateful acknowledgment is also given to the British National Committee for the Prevention of Blindness and the Royal National Institute for the Blind. The authors thank Dr John Marshall, of the Institute of Ophthalmology, and Dr June Almeida, of the Wellcome Research Laboratories, for their invaluable help with the histological preparations and the identification of the virus. Anna Taylor prepared the manuscript.

\section{References}

1 Peyman GA, Meisels HI, Batko KA, Vicheck JK. Full thickness eye wall biopsy, I. An experimental approach to the tissue diagnosis and study of choroidal and retinal lesions. Invest Ophthalmol Visual Sci 1975; 14: 484-7. 
2 Peyman GA, Homer P, Kasbeer R, Vicheck JK. Full thickness eye wall biopsy. II. In primates. Invest Ophthalmol Visual Sci $1975 ; 14: 565-7$.

3 Griffin JR. Straatsma BR. Kreiger AE. Transvitreal chorioretinal biopsy in the rabbit. Am J Ophthalmol 1975; 79: 25-38.

4 Peyman GA. Fishman GA. Sanders DR. Apple DJ, Vicheck JK. Biopsy of human scleral-chorioretinal tissue. Invest Ophthalmol Visual Sci 1975; 14: 707-10.

5 Constable IJ. Problems of chorioretinal biopsy. Proc R Soc Med 1980; 73: $1-5$.

6 Constable IJ. Slatter DH, Horne R. Chorioretinal biopsy in dogs. Invest Ophthalmol Visual Sci 1979; 19: 603.

7 Constable IJ. Chester GH. Horne R. Harriott JF. Human chorioretinal biopsy under controlled systemic hypotensive anaesthesia. Br J Ophthalmol 1980; 64: 559-64.

8 Craighead JE. Kanich RE. Almeida JD. Nonviral microbodies with viral antigenicity produced in cytomegalovirus-infected cells. J Virol 1972; 10: 766-75.

9 Talbot P. Almeida JD. Human cytomegalovirus: purification enveloped virious and dense bodies. J Gen Virol 1977; 36: 345-9.

10 Baehner RL. Hematologic malignancies; leukemia and lymphoma. In: Miller DR, Preston HA. Baehner RL. McMillan CW, eds. Smith's Blood Diseases of Infancy and Childhood. St Louis: Mosby, 1978: 588-646.

11 Vietti TJ, Land VJ, Abdelsalam HR. Management of acute leukemia. In: Sutow WW. Vietti TJ. Fernbach DJ, eds. Clinical Pediatric Oncology. St Louis: Mosby, 1977: 334-70.

12 Norton SW. Stockman JA. Unilateral optic neuropathy following vincristine chemotherapy. J Pediatr Ophthalmol 1979; 16: 190-3.
13 Sanderson PA, Kuwubara T, Cogan DG. Optic neuropathy presumably caused by vincristine therapy. Am J Ophthalmol 1976; 81: 146-50.

14 Shukovsky LJ. Fletcher GH. Retinal and optic nerve complications in a high dose irradiation technique of ethmoid sinus and nasal cavity. Radiology 1972; 104: 629-34.

15 Starr SE.. Cytomegalovirus. Pediatr Clin North Am 1979; 26: 283-93.

16 Diddie KR. Schanzlin DJ, Mausolf FA, Minchler DS. Trousdale MD. Necrotising retinitis caused by opportunistic virus infection in a patient with Hodgkin's disease. Am J Ophthalmol 1979; 88: 668-93.

17 Broughton WL. Cupples HP. Parver LM. Bilateral retinal detachment following cytomegalovirus. Arch Ophthalmol 1978; 96: 618-19.

18 Marmor M, Egbert P. Egbert S, Marmor J. Optic nerve head involvement with cytomegalovirus in an adult with lymphoma. Arch Ophthalmol 1978; 96: 1752-4.

19 Rytel MW. Aaberg TM. Dee TH. Heim LH. Therapy of cytomegalovirus retinitis with transfer factor. Cell Immunol 1975; 19: $8-21$.

20 Thomas IT, Soothill JF, Howkins GT, Marshall WC. Transfer factor treatment in congenital cytomegalovirus infection. Lancet 1977; ii: $1056-7$.

21 Overall J, Kern E, Glasgow L. Effective antiviral chemotherapy in CMV infection of mice. J Infect Dis 1976; 133 (suppl): 237-44.

22 Arvin AM. Yeager AS, MeriganTC. Effect of leukocyte interferon on urinary excretion of CMV by infants. J Infect Dis 1976; 133 (suppl): 205-10. 